\title{
Jan Beccaloni: Arachnids
}

\section{CSIRO Publishing, Collingwood, Victoria, 2009, 320 pp, Hardback, Au\$69.95, ISBN 9780643096974}

\author{
Tim R. New
}

Published online: 30 October 2009

(C) Springer Science+Business Media B.V. 2009

The variety of arthropods included in Arachnida comes as a surprise to the many people who equate the term with 'spiders', and much of the importance of this lavishly illustrated survey of the group is to dispel this notion by providing accounts of all 11 orders. Nevertheless, just two of these, Araneae and Acari, indeed comprise around 90\% of described arachnid species whilst, at the other extreme, Ricinulei (55 species) and Palpigradi (82) contain relatively few. The first, introductory, chapter is a broad account of body structure and biology of arachnids and, although a summary table contains some characteristics of each order, I felt that two augmentations would have been very useful for readers encountering arachnids for the first time or unfamiliar with some of the orders. First, a simple key to orders would be invaluable in differentiating these. Second, the various cladograms used to demonstrate schemes for ordinal relationships are not attributed individually to particular authors, so that the brief accompanying text (the most densely referenced page of the book) provides some difficulties in alluding to these. I also felt that a fuller treatment of ecology would have been informative-a brief (10 lines) comment on 'habitats' is inevitably very general, and no treatment of rarity or conservation needs is presented, other than by casual allusions. Thus, on p. 54, we are told that Dolomedes plantarius is 'Sadly ... now listed as vulnerable on the World Conservation Union's Red List of Threatened Species', but this isolated comment is not developed elsewhere. In view of the author's significant role as Conservation Officer for the British Arachnological

T. R. New $(\bowtie)$

Department of Zoology, La Trobe University, Melbourne,

VIC 3086, Australia

e-mail: T.New@latrobe.edu.au
Society, I was anticipating stronger conservation messages to flow in this book-and I feel that a good opportunity to do this has been missed.

That said, as relevant to readers of this Journal, a wealth of information on each order is present, in non-technical language, to result in a very readable text. For each order, sections on Classification and Diversity (with individual comments on major groups and relationships) are followed by treatments of special themes of structure and biology, with numerous subheadings helping readers focus from the abbreviated book contents listing of order and common names alone. As befits their richness, spiders and mites/ticks have the longest chapters. Many of the excellent photographs in all chapters are of living animals, but a few legends to drawings and photographs need attention-as examples, the 'cross section' of an opilionid (p. 219) appears to be a median longitudinal section, and the prey of the funnelweb spider (p. 30) is a skink, rather than a 'kink' lizard. This well-produced and attractive book is a valuable source for information on arachnids and, although the text itself is not closely referenced, includes references to publications and websites for each chapter, preceding an index and short glossary. However, it ends rather abruptly (with a paragraph on longevity of the Solifugae, as the final order treated), and I missed a concluding summary chapter that could have brought together many of the disparate facts presented on each order into a major synthesis of arachnid ecology and distribution. The wealth of facts and information presented in each chapter deserves such integration. 